\title{
Mapping Compulsive Buying Behavior of M-commerce Consumers in Pakistan
}

\author{
MUHAMMAD USHA MALIK \\ Air University School of Management (AUSOM), Islamabad Pakistan. \\ Email: m.usha.malick@gmail.com \\ Dr. SHAFEI MOIZ HALI \\ Assistant professor, Department of Government \& Public Policy, \\ National Defence University, Islamabad, Pakistan. \\ Email: Shafei.hali@yahoo.com \\ MUHAMMAD AIZZAN MALIK \\ Visiting Faculty, Department of Political Science, \\ Government College University, Lahore, Pakistan. \\ E-mail: aizzan_malik@yahoo.com
}

\begin{abstract}
In the last decade, emergence of different technological platforms have drastically influenced and altered societies across the globe. Social commerce or S-commerce which is an off shoot of e-commerce has become part of everyday life among consumers. Mobile commerce also known as m-commerce is a major contributor towards S-commerce. The current research intends to investigate the compulsive buying behavior and conspicuous online consumption frameworks in the context of $m$-commerce. This study is targets the trends of $m$ commerce within the context of developing country like Pakistan. The current research aims at highlighting how the antecedents involved in the frameworks of compulsive buying behavior and conspicuous online consumption translate into behaviors in the context of m-commerce. The significance of the study can be judged from the fact that, it will help contribute towards to body of knowledge concerning modern social consumptions patterns of the consumers triggered by the $m$ commerce applications. The research utilizes the lens of the social impact theory with peers and $m$ commerce, based on the SOR model. The selected population for undertaking the study comprised of consumers who consume different products (i.e. apparel, gadgets, cosmetics and jewelry etc.). This study has diverse theoretical and managerial contribution in the field of consumer behavior. As the results of this study also validated the SOR model and as well as social impact theory in the context of the m-commerce. Secondly, this study taken participation and desire for self-promotion as an organism. And participation was directly inclined by the familiarity and closeness.
\end{abstract}

Keywords: S-commerce, Compulsive Buying Behavior, Conspicuous Online Consumption, Social Impact Theory, SOR Model.

\section{Introduction}

Technological advancements have influenced global societies. The impact of technological advancements is immense on the communities of societies. With the creation of new technological methods and algorithms the access to all kinds of information is available almost instantly. Electronic commerce has evolved in the last decade due to the technology penetration in the business domain. The subset of electronic commerce that is social commerce is majorly used and preferred by the consumers of products 
and services. The significant contribution has been made by the mobile commerce in social commerce. According to Statistica (2018), around 3.3 billion people across the globe have smartphones. This huge usage base of smartphones has a significant effect on the consumption behavior of the consumer. As the users of smartphones are more integrated with each other and the consumers are influenced by one another, have a significant effect on each other's life.

In 2017, Leong found that impulsive buying behavior is triggered by Facebook-commerce. In their study they have articulated that the higher usage of Facebook leads towards higher inclination towards impulsive purchases. Leong et al, (2018) found out that impulsive buying performed by the Facebook-commerce user in the situation once they develop the urgency to buy the particular product or service, they have found that; hedonic, utilitarian and trust are key motivators of the urgency. Online reviews of different products and services by the social media peers prompt the hedonic and perceived value which leads towards urge to purchase and urge to promote the formation of the impulse buying behavior (Zhang, Xu, Zhao \& Yu, 2018).

According to Taylor and Strutton (2016), higher usage level of Facebook also increases the level envy among the participants, which leads to different attitudinal and behavioral formation, as they have found that higher level of envy leads towards the desire of self-promotion in the users which tilted them to participate in a conspicuous demonstration online consumption. Rizwan el at., (2014) found that In Pakistan, married and female respondents demonstrate more conspicuous consumption than the single and male respondent. They also determined that the respondents with lower incomes display more conspicuous consumption as compare to the higher income levels.

Social networking sites are the source of behavioral change in the consumers for purchasing the products. The social networking sites are used for the purchasing research and in few last years the use of SNS has increased. The previous researches have covered the aspects of consumer behavior pertaining to use of social networking sites. The researches have been conducted for the negative behavior of purchasing by the consumers and impulsive behavior of purchasing of the consumers by the usage of mobile-commerce (Zhang, Xu, Zhao \& Yu, 2018; Leong, 2017; Leong, Jaafar \& Ainin, 2018). The research in the aspect of conspicuous online consumption and compulsive buying behavior can be researched for the consumer base of Pakistan that has not has been researched so far (Rizwan, Umair, Bilal, Akhtar \& Bhatti, 2014). The aspect of mobile commerce can be explored to study the compulsive buying behavior in Pakistan.

Pakistan is one of the growing economies of the world at a faster pace. Pakistan is one of the strongest locations in the world for the mobile industry. It is preferred for the retail and electronic retailing of smartphones. The technological transformation has created an impact on the evolution in the business sector and Pakistan can be become one of the largest economies in the world that is integrated in terms digital domain.

Pakistan can become the country with the most proficient users of smartphones in world. Pakistan had around 125 million mobile users by the end of year 2015, which transformed the business culture in the country and procedures of the business. The interaction between and businesses and consumers was also transformed due to mobile technology. Smart phones have taken over the mobile industry. Nearly $31 \%$ of the market comprised of smart phones back in 2015 which is a completely different scenario now. The penetration of the smartphones in the industry has increased thus creating significant impact on business and operation models (Imtiaz, Khan \& Shakir, 2015).

According to German market research institute Pakistan is the sixth growing market in the smartphone industry surpassing UK or USA. The increased value in the growth is due to innovation in the telecommunication technology and launch of 3G/LTE technologies in Pakistan (Sheikh, Zafar, Pervez \& Bhutta, 2016). In Pakistan, the ratio of smartphones users is greater in comparison to Indian users as per population of the countries. In the year 2015-2016 the sales of the smartphones increased to 780 percent in 
Pakistan (Imtiaz, Khan \& Shakir, 2015). In Pakistan, the population below the age of 30 is around $77 \%$ and is the frequent user of technology. Nearly 80 percent spend time daily on online community. The potential for the online aspects is far greater in this segment of population. The social networks are being used for education and influence for the segment of population. For example the usage of Facebook has increased as the technology facilitates easy access to the application through smartphones and contact numbers only. Murphy et al, (2017) discussed that the usage of the Google search engine on the mobile devices is nearly $76 \%$ in Asia.

This research undertakes the compulsive buying behavior and conspicuous online consumption behavior frameworks, as this behavioral outcome with their key antecedents has not been tested through mobilecommerce phenomena in the context of Pakistan. This research also explores how these antecedents involved in the formation of these behaviors in the context of mobile-commerce. The objective of this study is to understand the modern social consumptions patterns of the consumers triggered factors by the mobilecommerce applications. This study also give the unique view of the negative behavioral outcomes in the context of Pakistani consumers as Pakistan is a part of developing nations of the world with the steady economic growth rate (MoF, 2018).

\section{Significance of the Study}

The development of social networking sites and online commerce has created another dimension of research which is to be explored yet. There is potential in the study of mobile-commerce related to its extensive use and the negative behavior outcomes. As the phenomena of the mobile-commerce is relatively new (i.e. is not more than ten years old), most of the research conducted on this phenomena is related to the formation of the consumption behavior and less research has been carried out on the domain of negative behavioral outcomes. The study will present the quantitative analysis to reflect on the significance of impact of mobile commerce on the buying behavior. The study covers the theoretical model and validates it through the statistical analysis. The different factors that create the significance impact on buying behavior through mobile commerce have been reflected in the research.

\section{Literature Review}

\section{Theoretical Background}

According to Goffman (1959), the classic theory of self-penetration covers the concept of human interaction and impressions that are created or regulated on others. According to Swan (1989), the selfverification theory highlights people like to stick their views and there is drive to consolidate and alleviate the views. Kaplan (1975) states that people behave with the idea of self-derogation, since they indulge in the negative views about themselves; they also interact with others to discuss negative information and feedback about themselves. Majorly most of the people have positive self-views (Diener \& Diener, 1995). The theorists of self-verification anticipate that most of the people will reflect positively about themselves to represent those (Kwang \& Swann, 2010).

To inform the researched explanations, the use of theories as social cognitive theory, social capital theory (Chiu et al., 2011); social exchange theory (Faraj \& Johnson, 2011); sunk cost theory (Tiwana \& Bush, 2005); the technology acceptance model (Venkatesh, 2000); theories of social network and Social Network Analysis (Faraj \& Johnson, 2011); critical mass theory (Raban, Moldovan,\& Jones, 2010) and resourcebased theory (Butler,2001). Through these theories, previous studies have provided different perspectives influenced by such areas as psychology, sociology, information technologies, organizational studies, humane computer interaction." 


\section{Compulsive Buying Behavior}

According to Edward and Porter (1992) compulsive buying behavior is represented by the "anomalous behavior of shopping that is extreme and irrepressible in nature. The need of spending repetitively to purchase ignoring the outcomes is higher ". Another definition of compulsive buying is "an uncontrolled behavior in shopping that results in cumulative financial and social difficulties" (Maraz, Kiraly, \& Demetrovics , 2015)".

Compulsive buying demonstrates various patterns as suggested by the past researches. The everyday basic need is the basic pattern pertains to compulsive buying. If the individual feel pleasant by the purchase of the product based on the compulsive buying, it refers to the emotional buying pattern. If a purchase is motivated by the individual's socializing needs, it refers to the social buying pattern. Lastly, an unconscious motivation to purchase the item is refers to the self-buying pattern (Jung et al, 2014)."

Compulsive buying disorder is the outcome of accustomed behavior of getting pleasure and satisfaction from purchasing and as a resultant the need to purchase increases to gain the enjoyment and happiness in the theory of behavior (Presskorn- Thygesen \& Bjerg, 2014). The theory of culture reflects that compulsive buying has grown as a cultural norm openly and makes the need of purchasing collections redundantly and unnecessarily (Roberts \& Martinez, 1998; Bushra \& Bilal, 2014).

Uncontrollable buyers often trait their recurring purchasing to inner causes such as evading or trying to recover bad frame of mind (Miller, 2007). Abundant researches have scrutinized the association among compulsive buying disorder and grim indicators, resulting that were unswervingly interconnected (Black, Shaw, Mccormick, Bayless \& Allen, 2012; Mueller et al., 2010; Sohn \& Choi, 2014). Correspondingly, compulsive buying is expressively interconnected with medical melancholy and other mood maladies (Muller et al., 2014). Kesebir, Işitmez, and Gündoğar (2012) also establish correspondences among compulsive buying malady and melancholy, angst, resentment, monotony, and obsessiveness. Moreover, researchers have discovered substantial gender variances in compulsive buying, with obsessive shoppers were probably more feminine than masculine (Annagur \& Tamam, 2011; Barakat, 2005; Maraz, van Brink \& Demetrovics, 2015; Müller et al., 2014). Zheng et al 2020, support the above argument and identified that if the stress level is high than more inclination towards the CBB. Conversely, additional researches (Koran, Faber, Aboujaoude, Large, \& Serpe, 2006; Mueller et al., 2010) establish no such gender variances." Biswas et al 2019 establish that the high user of the internet shows the compulsive buying behavior. Internet addiction among the young consumer is also one biggest cause compulsive buying behavior (Zhang et al 2019). Ouyang et al 2020, the high usage of smart phone also increase the compulsive buying among the students.

\section{Conspicuous Online Consumption}

Exhibiting about a buying on social media can be seen as the contemporary and digital practice of flamboyant consumption as it displays one's possessions to depict, preserve or expand communal prominence via overtly used merchandises as a standing (Duan \& Dholakia, 2017). Due to the progression in technology, shoppers today have entrance to platforms that assist them in exhibiting their buying and application practices (Kim et al., 2016)."

Gierl and Huettl (2010) fix three principle characteristics of noticeable consumption, which are: 1. socially discernible accession and utilization. 2. Assertion of prestige, individuality, or orthodoxy to the appropriate others. 3. Purchase and expenditure of inadequate capital goods."

As a consequence, unlike goods those are more frequently sought out for basic needs, flamboyant goods are purchased and utilized not only for functional purposes but also as a representation of social status for the reason that they can be ornately displayed in front of others (Lewis \& Moital, 2006)." 
The term conspicuous consumption was originally fabricated by Veblen (2005) in accordance with the behavior of consuming time and money on unnecessary and unfruitful activities. Chaudhuri et al. (2011), put in additional accentuation on the utilization for self-presentation, and explained it as a Pat in figurative purchase and expenditure of inadequate and cultural capital goods to show a distinguishing self-image in front of others. The concept of leisure class theory highlights that "people use the services and products that are noticeable to accomplish the caving to improve status" (Veblen, 1994).

Communal-oriented individuals will prefer to consume conspicuous products when they experience social exclusion rather than social inclusion and that this behavior is driven by self-esteem evoked from comparing differences of self-orientation (Liang, He, Chang, Dong \& Zhu, 2018). Upward social comparison, as opposed to downward comparison, increased preference for the conspicuous consumption (Zhang, Xu, Zhao \& Yu, 2018). Consumers' tendency for conspicuous consumption is positively related to both functional food category evaluation in terms of its distinctiveness and self-reported purchase rates of functional foods (Barauskaite et al., 2018). Beneli 2019, cultural values also inclined the consumer to conspicuously consume the goods.

\section{Desire for Self-Promotion}

Desire for self-promotion (DSP) is define as "People employ varying self-presentation strategies both during face-to-face interactions and online" (Schlenker \& Pontari, 2000)." The need for self-presentation on SNS has been found to be related to personality traits such as neuroticism, narcissism, shyness, selfesteem, and self-worth (Marshall, Lefringhausen, \& Ferenczi, 2015; Nadkarni \& Hofmann, 2012). For example, extroversion and narcissism were found to be reflected by excessive online self-promotion. Neuroticism was found to be related to ideal and false self-presentation (Michikyan, Subrahmanyam, \& Dennis, 2014). A significant link was found between some dimensions of narcissism and specific categories of selfies taken by participants (Barry, Doucette, Loflin, Rivera-Hudson, \& Herrington, 2015). Spending time on SNS profiles causes young people to endorse positive self-views, sometimes narcissistic ones (Gentile, Twenge, Freeman, \& Campbell, 2012). Taylor 2020, found out that high usage of the social media platforms inclined the person for self promotion.

\section{Participation}

Participation (Pat) in an online community determines community success in the long term (Koh \& Kim, 2004) because Pat promotes long-lasting relationships among community members (Algesheimer, Borle, Dholakia \& Singh, 2010). Greater Pat implies a higher level of involvement with the online community, which may reinforce the feelings that bind each member to the other community members, improve instruction on communal values, encourage conjoint behaviors and information sharing, and enable stronger group cohesion (Casaló, Flavián \& Guinalíu, 2010).

The researches have been carried out for two dimensions of participation the first as the extent of participation and second as amount of active contribution. The extent of the participation is measured by the frequency of time duration of visiting the pages that reflects upon the quantitative data of participation. The second dimension of participation is measured with the active community on the Facebook pages. The nature of contribution and behavior of contribution towards participation is analyzed covering the qualitative aspect for participation (Rachel et al., 2018). Lee et al 2020, found that the high participation of consumer in the online shopping and social media had underwrote to the rise of social shopping activities.

\section{Closeness \& Familiarity}

The feeling of closeness (CLO) and emotional bonding is involving intense liking and moral support from social network friends, and the ability to tolerate social network friends' mistakes. The feeling of 
familiarity (FAM) between social network friends is often based on previous interactions, experiences, and learning of what, who, whom, how, when, and why of what is happening. (Ng, Chaya, \& Hort, 2013)”.

According to $\mathrm{Ng}$ et al. (2013), social interaction may breed closeness and familiarity and a member with higher social interaction with others will have more intense feeling of familiarity and closeness with others. With more social interactions it will bring about stronger trust within the community since familiarity and closeness may assist consumers to feel more secure. Besides, social interactions will affect an individual's trust because these interactions will nurture higher commitment, involvement and sense of belonging."

A number of researches have investigated the impacts of familiarity on consumers' behavior, brand evaluations and behavioral intentions (Arora \& Stoner, 1996; Coupey et al., 1998; Dahl et al., 2001; Söderlund, 2002). Familiarity is also a topic of interest in researches pertaining to branding and advertising (Allen, 1994; Campbell et al., 2003; Hardesty et al. 2002; Tybout and Meyers-Levy, 1989)".

\section{Hypotheses of Study}

H1: Closeness (CLO) among mobile commerce consumers shares positive significant relationship with participation.

H2: Familiarity (FAM) among mobile commerce consumers shares positive significant relationship with participation.

H3: Participation (Pat) among mobile commerce consumers shares positive significant relationship with desire for self-promotion

H4: Desire for self-promotion (DSP) has positive significant relationship with conspicuous online consumption (COC) among mobile commerce consumers.

H5: Desire for self-promotion (DSP) has positive significant relationship with compulsive buying behavior (CBB) among mobile commerce consumers.

\section{Research Methodology}

\section{Theoretical Framework}

The Stimulus-Organism-Response (S-O-R) model given by Mehrabian and Russell (1974) is use to constitute conceptual framework of the study. The behaviors like COC and CBB are the responses (R) resulted by the consumer (organism; O) which are also be stimulated by the environmental stimuli ( $\mathrm{S}$ ) (Mehrabian and Russell 1974). According to Eroglu et al, (2003), The Individual which can be stimulated by the influence can be conceptualized as those elements that affect the individuals' inner state are defined as the stimuli in the classical S-O-R model. Both marketing mix variables and other environmental inputs are the external stimuli of the individual, when consumer behavior is illustrated as an S-O-R M (Bagozzi 1986),. According to Latané, (1981), the effect of any wellspring of data could be because of the quantity of people who shaped the source, the CLO of the source to the collector amid the time of the impact endeavor and the tie control between the source and the beneficiary, this whole situation is the social impact on the consumers' behavior also known as the SIT. So, this social impact (i.e. CLO and FAM with the m-commerce peers) become the external environments' stimuli effect the attitude (i.e. Pat and DSP) of the customer in this manner that the organisms' response is the negative behavioral outcome such as the $\mathrm{COC}$ and $\mathrm{CBB}$. 


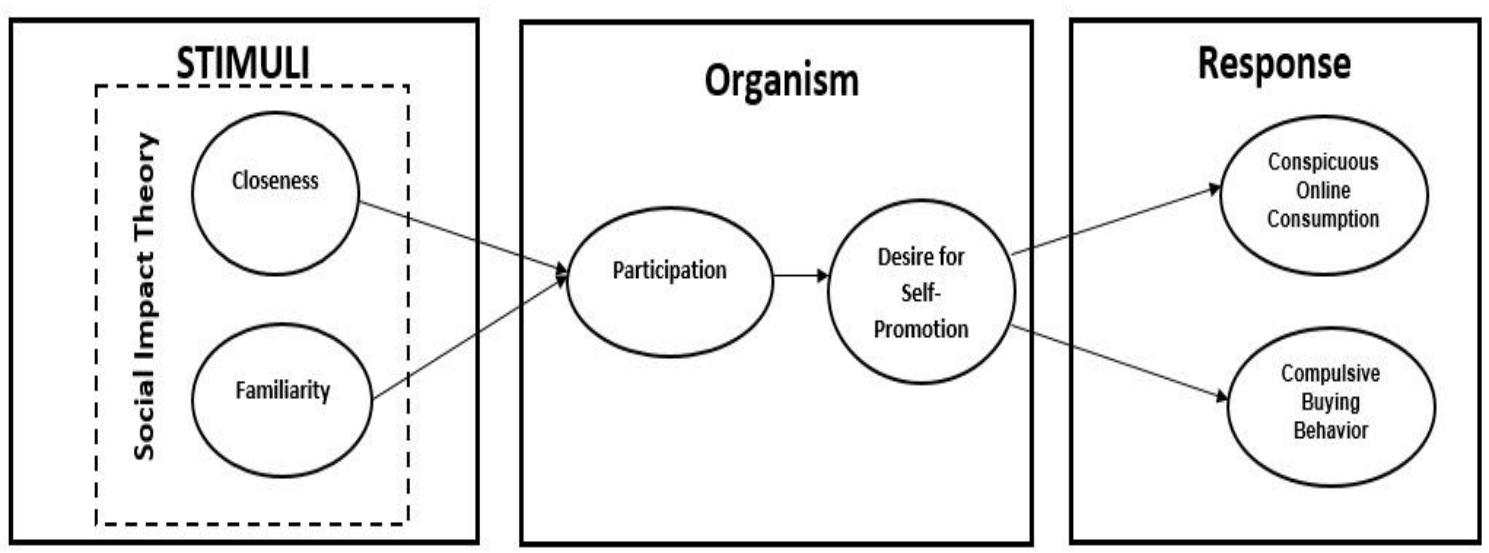

Figure 1: Conceptual Framework

\section{Survey Methodology}

For this study, Population was the buyers of different products (i.e. apparel, gadgets, cosmetics and jewelry etc.) which were directed by the social networking platforms to the respected s-commerce platforms. The convenience sampling technique was used to draw sample from the targeted population. According to Statista (2020), there are 39 million users present in Pakistan which uses different social networking platforms and the population below the age of 30 is around $77 \%$ and is the frequent user of technology. The data was collected from the consumers which were using different social networking mobile apps, questionnaire were distributed through google forms of different universities of Islamabad and Rawalpindi (i.e. National Defense University, Air University, Baheria University, Preston University, and Iqra University). For the ethical consideration and to control the researcher biasedness, questionnaires were distributed among the respondents through the program coordinators of the targeted universities. Aggregate 410 questionnaires were distributed among the respondents from which 323 were received back. There were only 273 complete questionnaires included in this study.

\section{Measures}

$\mathrm{Ng}$ et al, (2013) scales were adapted which includes 3 and 4 items to measure CLO and FAM respectively. The Pat was measured through Casaló et al. (2010) scale which have 4 items. Bolino and Tunley (1999), scale was adapted to measure DSP, which have 5 items. Eastman \& Goldsmith (1999) scale was adapted which have 5 items to measure COC. CBB was measured through, Valence et al. (1988) scale which have 5 items. Responses were taken on five point likert scale of all items.

Table 1: Summary of Measures

\begin{tabular}{|lll|}
\hline Variables & Instrument Authors & No of items \\
\hline CLO & $\mathrm{Ng}(2013)$ & 3 \\
FAM & $\mathrm{Ng}(2013)$ & 4 \\
Pat & Casaló et al. (2010) & 4 \\
DSP & Bolino et al. (1999) & 5 \\
COC & Eastman et al. (1999). & 5 \\
CBB & Valence et al. (1988) & 5 \\
\hline
\end{tabular}

\section{Procedure}

To analyze the data, partial least square structural equation modeling (PLS-SEM) technique was employed. There was two steps procedure recommended by Hair et al. (2014) for PLS-SEM. Measurement model 
analysis was the first step and structural model analysis was the second step. To analyze the data smart PLS software version 3.0 was employed.

\section{Results}

\section{Sample Description}

273 respondents who used different mobile apps for shopping were the sample of this study. Descriptive of the sample of this study indicated that $53.7 \%$ responses were from males and $46.3 \%$ responses were from females. However 89 shoppers were fall into the age bracket of 24-29 years. Utmost, 115 of the shoppers have 14 to 16 years of education. 84 respondents were students and also employed in different organizations. Data was normally distributed because Kurtosis and Skewness values were between range of -2 and 2 , which were displayed in Table 2 .

Table 2: Profile of Demographic Variables

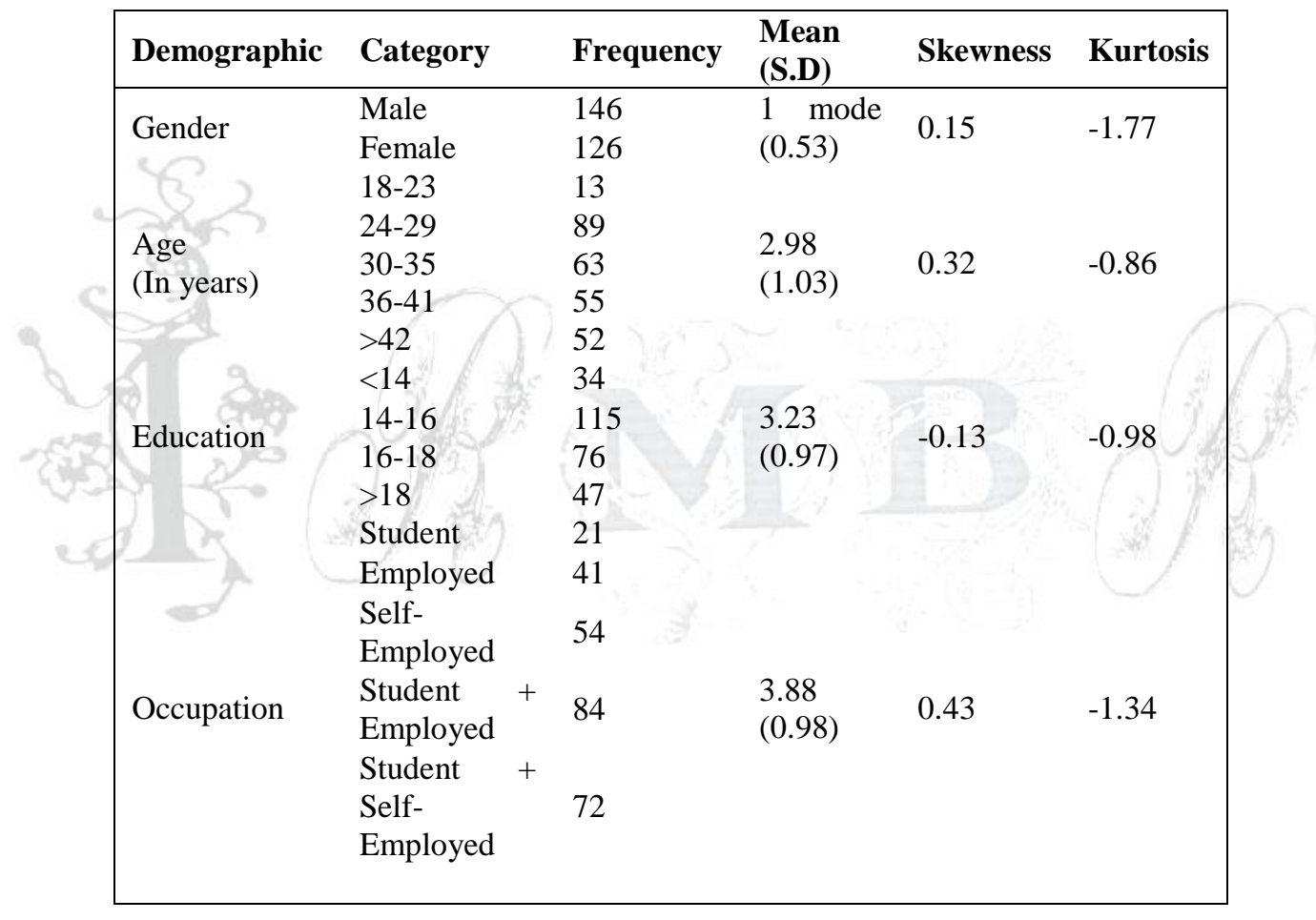

\section{Measurement Model Analysis}

The measurement model was analyzed through validity, convergent and discriminant validity was established, and reliability, Cronbach's alpha and composite reliability was measured.

Latent variables of this study were observed to found out the internal consistency, composite reliability and Cronbach alpha were two test applied on this study. Values of outer loadings of observed variables were checked to establish the composite reliability. Covariance among items, and average variance were established on the basis of the values of Cronbach alpha. The value of composite reliability and Cronbach alpha should be higher than 0.60 . Outcomes are represented in Table 3 . 
Table 3: Results of Measurement Model Analysis

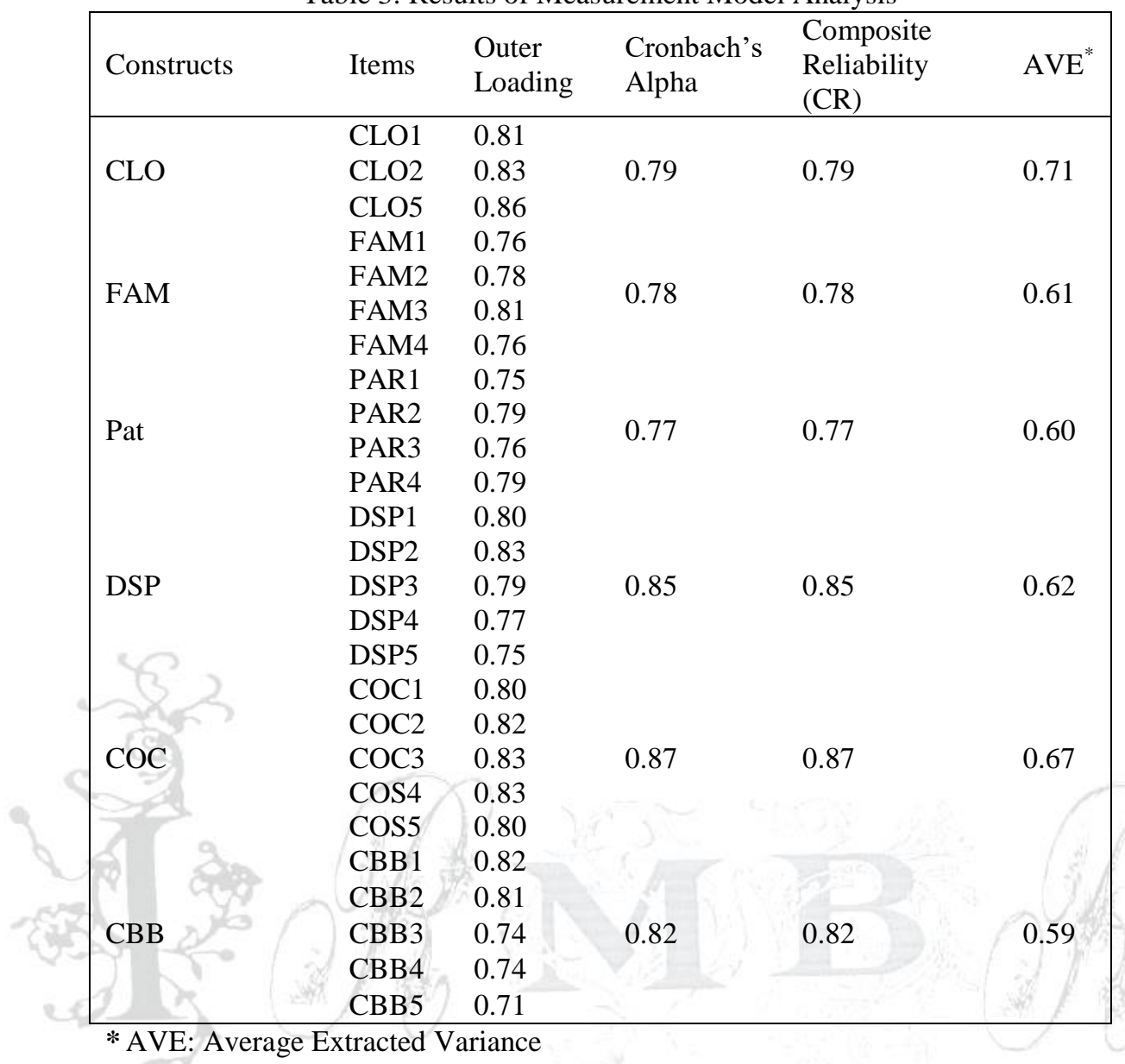

The convergent validity was comprehend through average variance extracted (AVE). The variables which should be related are related, were evaluated through convergent validity analysis. AVE value should be greater than 0.50 as suggested by Hair et al. (2010). Convergent validity analysis were represented in Table 4.

\begin{tabular}{|cccccccc|}
\hline \multicolumn{7}{|c|}{ Table 4: Fornell-Larcker Discriminant } & Validity and Correlation Analysis \\
\hline Constructs & 1 & 2 & 3 & 4 & 5 & 6 \\
1. & CLO & $\mathbf{0 . 8 4}$ & & & & & \\
2. & FAM & 0.58 & $\mathbf{0 . 7 8}$ & & & & \\
3. & Pat & 0.60 & 0.53 & $\mathbf{0 . 7 7}$ & & & \\
4. & DSP & 0.47 & 0.53 & 0.42 & $\mathbf{0 . 7 9}$ & & \\
5. & COC & 0.63 & 0.67 & 0.53 & 0.58 & $\mathbf{0 . 8 2}$ & \\
6. & CBB & 0.60 & 0.73 & 0.56 & 0.53 & 0.65 & $\mathbf{0 . 7 6}$ \\
\hline
\end{tabular}

That variables that should be unrelated are unrelated were checked through discriminant validity measure. In other words, discriminant validity was used in this study to measure the variance among underlying variables. To test the discriminant validity, Fornell-Larcker criterion was employed in this study. The square root of AVE of all variables were compared with the correlation values among the latent variables, the criterion was established. Outcomes are represented in Table 4. 


\section{Structural Model Analysis}

Structural model analysis was executed for the measurement analysis of the proposed conceptual model of the study. Structural path analysis, and R2 analysis were executed in the structural model assessment. Structural model was analyzed to examine the hypotheses of the study. The results of H1 indicates that CLO was influencing $44 \%$ on the Pat and the P-value of the hypothesis was less than 0.05 . H2 result exhibited that FAM had affirmative stimulus on the Pat as their Path $\beta$ is 0.28 and P-value is 0.00 (i.e. is less than 0.05). The results of $\mathrm{H} 3$ demonstrated that Pat is affirmatively stimulate at $42 \%$ to desire to selfpromote with $0.00 \mathrm{P}$-value (i.e. is less than 0.05 ). DSP was affirmatively effect the COC with path $\beta$ of 0.57 and P- value of 0.00 (i.e. is less than 0.05), as it was hypothesized in the H4. The outcomes of H5 revealed that DSP was affirmatively impacted on the CBB with the path $\beta$ of 0.53 and the P-value of 0.00 (i.e. is less than 0.05). Effects are represented in Table 5.

Table 5: Results of Structural Model

\begin{tabular}{|lllll|}
\hline \multirow{2}{*}{ Hypothesis } & Path & $\beta$ & $\mathrm{p}$ & \multirow{2}{*}{ Decision } \\
\hline H1 & CLO $\rightarrow$ Pat & 0.44 & 0.00 & Accepted \\
H2 & FAM $\rightarrow$ Pat & 0.28 & 0.00 & Accepted \\
H3 & Pat $\rightarrow$ DSP & 0.42 & 0.00 & Accepted \\
H4 & DSP $\rightarrow$ COC & 0.57 & 0.00 & Accepted \\
H5 & DSP $\rightarrow$ CBB & 0.53 & 0.00 & Accepted \\
\hline
\end{tabular}

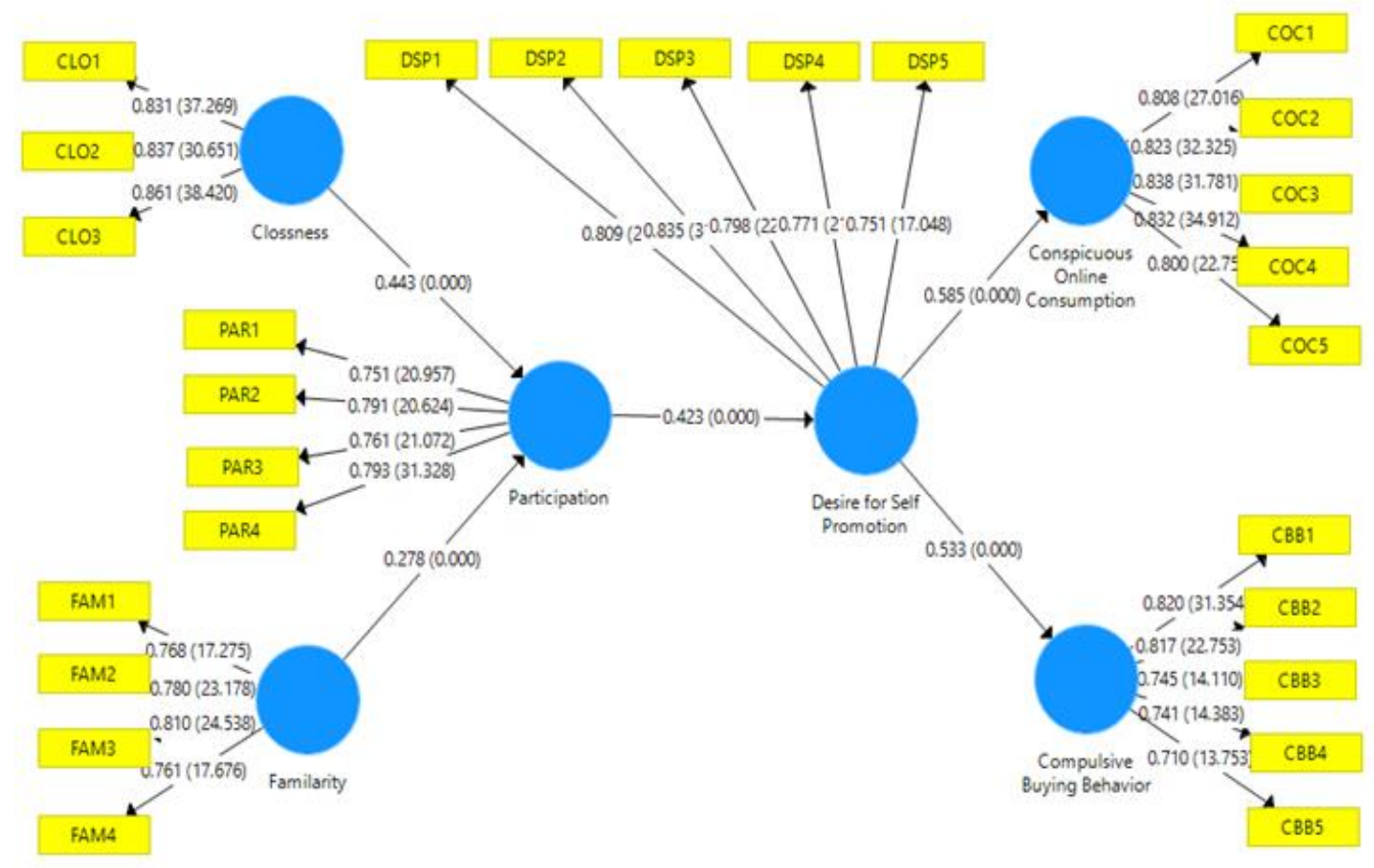

Figure 2: Structural Model

$\mathrm{R}^{2}$ of the model was analyzed to spot at which extent data was near the regression line. The value should be amid among 0 and 1 of $R^{2}$. Good model fit data indicates higher values. Pat $R^{2}$ assessment was 0.41 , DSP was 0.18 , COC was 0.34 , and for CBB was 0.26 . Results are represented in Table 6. 


\begin{tabular}{|ll|}
\multicolumn{3}{c}{ Table 6: $\mathrm{R}^{2}$ Analysis } \\
\hline Constructs & $\mathbf{R}^{2}$ \\
\hline Pat & 0.41 \\
DSP & 0.18 \\
COC & 0.34 \\
CBB & 0.28 \\
\hline
\end{tabular}

\section{Discussion and Implications}

\section{Discussion}

As previously, obtain results from this study are aligned with past researches. However, the results of $\mathrm{H} 1$ and $\mathrm{H} 2$ indicated that CLO and FAM unswervingly and affirmatively influence the Pat. These are contradicted to Ying (2017) and Leong et al., (2018) which had used trust motivation as additional path that influences the Pat in the context of f-commerce. In the context of M-commerce it was found out by these results that higher the CLO and FAM more the m-commerce consumer will be participating in the purchase. H3 stated that Pat directly and affirmatively influence the desire for self-promotion. The results of the $\mathrm{H} 3$ also supported that hypothecation as of Taylor (2016) also found out that envy and narcissism had a direct and positive effect on the DSP in the context of Facebook usage. As envy and narcissism were gained through the intensity of usage of Facebook which indicate that consumers have high Pat in their social media circle and they get influenced by this high association, which increase the desire of the consumer extend its self and effects its buying behavior (Taylor, 2016). H4a results indicated that DSP is positively impacted the COC. As these results also aligned with the findings of Taylor (2016) and Dev et al. (2018). In those studies, COC was directly influenced by the DSP in the online shopping environment. The outcome of $\mathrm{H} 4 \mathrm{~b}$ explains that DSP have a significant and affirmative effect on the CBB in the context of the mobile shopping environment. However, in the context of F-commerce Ying (2017) and Leong et al. (2018) found out that urge to purchase and urgency had influence impulsive buying behavior. As this study taken CBB as an outcome variable. Darrat et al 2016 found out that both impulsive and CBB shared the common antecedents as both were affected by the unplanned urges of the consumers. As Taylor (2016) found out that COC was impacted by the DSP which was also negative behavioral outcome as compulsive buying behavior.

\section{Implications}

\section{Theoretical Implications}

This study have diverse theoretical contribution in the field of consumer behavior. As compare to historical researches, this study undertake two theories (i.e. SOR Model and SI theory) and integrated into one. As the literature survey undertaken in this study, it was found out that SI theory was not taken as environmental stimulus in the SOR model. As the results of this study also validated the SOR model and as well as SI theory in the context of the m-commerce. Secondly, this study taken Pat and DSP as an organism. And Pat was directly inclined by the FAM and CLO, which was historically observed by the indirect path in which the variable of trust motivation was employed (i.e. Ying, 2017 and Leong et al. 2018).

DSP was unswervingly and affirmatively by Pat, which indicated that high Pat of the consumer of the mcommerce generate a will to promote his/her shopping experience to others and get appreciated by them. This condition also triggered the obsessive nature of the consumer which leads to compulsive buying behavior. Thirdly, this study tried to fill all the gaps (i.e. Taylor 2016, Ying 2017, Leong et al. 2018 and Dev et al. 2018) which was identified by the literature survey of the study. 


\section{Managerial Implications}

There were three managerial aspects drawn from this study. Firstly, marketing specialists of those organizations which are using different $\mathrm{m}$-commerce platforms (i.e. apps) can indorse trust factors on these platforms. As consumers of m-commerce have high CLO and FAM with each other can create a domino effect on sales or consumption of these products and services. These consumers have elevated interaction level with each other, create large number of effects on the consumption which can be further elevated by the trust in the presence of CLO and FAM. Secondly, level of Pat play pivotal role in the generation of the desire for self-promotion. In 2018, highest sales generated by Ali express in the product category wise was skin care products after that it was mobile phone accessories (i.e. phone covers, screens, etc.) (Statista, 2018). So, when the organizations are targeting the consumers of m-commerce, they should keep in their mind that these consumers can be easily attracted by those products which can extend the consumers self or help to satisfy their Id. Lastly, in the compulsive buying case, consumers which exerted obsessive and addictive nature can be easily attracted to m-commerce platform because there CLO and FAM to peers create high Pat levels which leads to their DSP which makes them to exerts compulsive behavior. These kinds of shoppers are easily attracted by different sales promotions and discounts but this leads to more difficult question i.e. how to convert this attraction to purchase into a long term relationship? The managers can obtain short term benefits from this relationship but literature of the relationship management does not coup with its long term aspects.

\section{Future Directions and Limitations}

Data of this study is collected cross sectional manner so this research can't evaluate the temporal effects of the consumer, as after the consumer gained the experience which type of the behavior will be formed can be measured through the longitudinal time horizon. This framework should be checked in different contextual settings to crate the generalizability. Other environmental stimulus such as the customer experience quality, trust etc. should be introduced in the conceptual framework of this study to create better understanding of the formation of negative behavioral outcome. In the organism, the variable of self-esteem and urgency should also be employed to further elaborate the formation of the negative behavioral outcomes.

\section{References}

Algesheimer, R., Borle, S., Dholakia, U. M., \& Singh, S. S. (2010). The impact of customer community participation on customer behaviors: An empirical investigation. Marketing science, 29(4), 756-769.

Annagur, B. B., \& Tamam, L. (2011). A Case of Comorbid Obsessive Compulsive Disorder and Compulsive Buying Disorder. Noropsikiyatri Arsivi-Archives of Neuropsychiatry, 48(1), 75-78.

Arora, R., \& Stoner, C. (1996). The effect of perceived service quality and name familiarity on the service selection decision. Journal of Services Marketing, 10(1), 22-34.

Bagozzi, R. P. (1986). Attitude formation under the theory of reasoned action and a purposeful behaviour reformulation. British Journal of Social Psychology, 25(2), 95-107.

Barakat, Z. (2005). Shopping psychology: A study of behaviour of buying and its relationship with few demographical variables in the Palestinian society. Najah University Humanities Journal,19(3), 953980.

Barauskaite, D., Gineikiene, J., Fennis, B. M., Auruskeviciene, V., Yamaguchi, M., \& Kondo, N. (2018). Eating healthy to impress: How conspicuous consumption, perceived self-control motivation, and descriptive normative influence determine functional food choices. Appetite, 131, 59-67.

Barry, C. T., Doucette, H., Loflin, D. C., Rivera-Hudson, N., Lacey, L., Barry, C. T., \& Herrington, L. L. (2015). Let me take a selfie": Associations between self-photography, narcissism, and self-esteem. Psychology of Popular Media Culture.

Ben-Shaul, M., \& Reichel, A. (2018). Motives, modes of participation, and loyalty intentions of Facebook tourism brand page consumers. Journal of Travel Research, 57(4), 453-471. 
Benli, B. (2019). A comparative study among Turkish and American consumers on the relationship between cultural dimensions and the two important outctmes of consumer society: Conspicuous consumption and online compulsive buying behavior.

Black, D. W., Shaw, M., McCormick, B., Bayless, J. D., \& Allen, J. (2012). Neuropsychological performance, impulsivity, ADHD symptoms, and novelty seeking in compulsive buying disorder. Psychiatry Research, 200(2-3), 581-587.

Bolino, M. C., \& Turnley, W. H. (1999). Measuring impression management in organizations: A scale development based on the Jones and Pittman taxonomy. Organizational Research Methods, 2(2), 187206.

Bushra, A., \& Bilal, A. (2014). The relationship of compulsive buying with consumer culture and postpurchase regret. Pakistan Journal of Commerce and Social Sciences (PJCSS), 8(3), 590-611.

Butler, K. D. (2001). Defining diaspora, refining a discourse. Diaspora: a journal of transnational studies, 10(2), 189-219.

Casaló, L. V., Flavián, C., \& Guinalíu, M. (2010). Determinants of the intention to participate in firmhosted online travel communities and effects on consumer behavioral intentions. Tourism management, 31(6), 898-911.

Coupey, E., Irwin, J. R., \& Payne, J. W. (1998). Product category familiarity and preference construction. Journal of Consumer Research, 24(4), 459-468.

Dev, M., Podoshen, J. S., \& Shahzad, M. (2018). An Exploratory Comparison of Materialism and Conspicuous Consumption in Pakistan. Journal of International Consumer Marketing, 30(5), 317-325.

Diener, E., \& Fujita, F. (1995). Resources, personal strivings, and subjective well-being: a nomothetic and idiographic approach. Journal of personality and social psychology, 68(5), 926.

Duan, J., \& Dholakia, R. R. (2017). Posting purchases on social media increases happiness: the mediating roles of purchases' impact on self and interpersonal relationships. Journal of Consumer Marketing, 34(5), 404-413.

Eastman, J. K., Goldsmith, R. E., \& Flynn, L. R. (1999). Status consumption in consumer behavior: Scale development and validation. Journal of marketing theory and practice, 7(3), 41-52.

Edwards, D., \& Potter, J. (1992). Discursive psychology (Vol. 8). Sage.

Eroglu, S. A., Machleit, K. A., \& Davis, L. M. (2003). Empirical testing of a model of online store atmospherics and shopper responses. Psychology \& marketing, 20(2), 139-150.

F. Hair Jr, J., Sarstedt, M., Hopkins, L., \& G. Kuppelwieser, V. (2014). Partial least squares structural equation modeling (PLS-SEM) An emerging tool in business research. European Business Review, 26(2), 106-121.

Faraj, S., \& Johnson, S. L. (2011). Network exchange patterns in online communities. Organization science, 22(6), 1464-1480.

Gentile, B., Twenge, J. M., Freeman, E. C., \& Campbell, W. K. (2012). The effect of social networking websites on positive self-views: An experimental investigation. Computers in Human Behavior, 28(5), 1929-1933.

Gierl, H., \& Huettl, V. (2010). Are scarce products always more attractive? The interaction of different types of scarcity signals with products' suitability for conspicuous consumption. International Journal of Research in Marketing, 27(3), 225-235.

Goffman, E. (1959). The moral career of the mental patient. Psychiatry, 22(2), 123-142.

Hair, J. F., William C. B., Babin, B. J., \& Anderson, R. E. (2010). Multivariate Data Analysis. Englewood Cliffs, NJ: Prentice Hall.

Hardesty, D. M., Carlson, J. P., \& Bearden, W. (2002). Brand familiarity and invoice price effects on consumer evaluations: the moderating role of skepticism toward advertising. Journal of advertising, 31(2), 1-15.

Hsu, M. H., Chang, C. M., Chu, K. K., \& Lee, Y. J. (2014). Determinants of repurchase intention in online group-buying: The perspectives of DeLone \& McLean IS success model and trust. Computers in Human Behavior, 36, 234-245.

Imtiaz, S. Y., Khan, M. A., \& Shakir, M. (2015). Telecom sector of Pakistan: Potential, challenges and business opportunities. Telematics and Informatics, 32(2), 254-258. 
Kaplan, H. B. (1975). Sequelae of self-derogation predicting from a general theory of deviant behavior. Youth \& Society, 7(2), 171-197.

Kesebir, S., İşitmez, S., \& Gündoğar, D. (2012). Compulsive buying in bipolar disorder: Is it a comorbidity or a complication?. Journal of affective disorders, 136(3), 797-802.

Ki, C. W., \& Kim, Y. K. (2016). Sustainable versus conspicuous luxury fashion purchase: Applying self-determination theory. Family and Consumer Sciences Research Journal, 44(3), 309-323.

Koh, J., \& Kim, Y. G. (2004). Knowledge sharing in virtual communities: an e-business perspective. Expert systems with applications, 26(2), 155-166.

Koran, L. M., Faber, R. J., Aboujaoude, E., Large, M. D., \& Serpe, R. T. (2006). Estimated prevalence of compulsive buying behavior in the United States. American Journal of Psychiatry, 163(10), 18061812.

Kwang, T., \& Swann Jr, W. B. (2010). Do people embrace praise even when they feel unworthy? A review of critical tests of self-enhancement versus self-verification. Personality and social psychology review, 14(3), 263-280.

Latané, B. (1981). The psychology of social impact. American psychologist, 36(4), 343.

Leong, L. Y. (2017). Examining the antecedents of impulse purchase among facebook commerce $(f$ commerce) users/Leong Lai Ying (Doctoral dissertation, University of Malaya).

Leong, L. Y., Jaafar, N. I., \& Ainin, S. (2018). The effects of Facebook browsing and usage intensity on impulse purchase in f-commerce. Computers in Human Behavior, 78, 160-173.

Leung, G. T. Y., Fung, A. W. T., Tam, C. W. C., Lui, V. W. C., Chiu, H. F. K., Chan, W. M., \& Lam, L. C. W. (2011). Examining the association between late-life leisure activity participation and global cognitive decline in community-dwelling elderly Chinese in Hong Kong. International journal of geriatric psychiatry, 26(1), 39-47.

Lewis, A., \& Moital, M. (2016). Young professionals' conspicuous consumption of clothing. Journal of Fashion Marketing and Management, 20(2), 138-156.

Liang, S., He, Y., Chang, Y., Dong, X., \& Zhu, D. (2018). Showing to friends or strangers? Relationship orientation influences the effect of social exclusion on conspicuous consumption. Journal of Consumer Behaviour, 17(4), 355-365.

Maraz, A., Király, O., \& Demetrovics, Z. (2015). Commentary on: Are we overpathologizing everyday life? A tenable blueprint for behavioral addiction research: The diagnostic pitfalls of surveys: If you score positive on a test of addiction, you still have a good chance not to be addicted. Journal of Behavioral Addictions, 4(3), 151-154.

Marshall, T. C., Lefringhausen, K., \& Ferenczi, N. (2015). The Big Five, self-esteem, and narcissism as predictors of the topics people write about in Facebook status updates. Personality and Individual Differences, 85, 35-40.

Meyers-Levy, J., \& Tybout, A. M. (1989). Schema congruity as a basis for product evaluation. Journal of consumer research, 16(1), 39-54.

Michikyan, M., Subrahmanyam, K., \& Dennis, J. (2014). Can you tell who I am? Neuroticism, extraversion, and online self-presentation among young adults. Computers in Human Behavior, 33, 179-183.

Miller, M. C. (2007). Commentary: Compulsive buying. Harvard Mental Health Letter. (Retrieved from) http://www.health.harvard.edu/newsletter_article/Commentary_Compulsive buying.

Mueller, A., Claes, L., Mitchell, J. E., Wonderlich, S. A., Crosby, R. D., \& De Zwaan, M. (2010). Personality prototypes in individuals with compulsive buying based on the Big Five Model. Behaviour Research and Therapy, 48(9), 930-935.

Müller, A., Claes, L., Georgiadou, E., Möllenkamp, M., Voth, E. M., Faber, R. J., ... \& de Zwaan, M. (2014). Is compulsive buying related to materialism, depression or temperament? Findings from a sample of treatment-seeking patients with CB. Psychiatry research, 216(1), 103-107.

Murphy, A., Farley, H., Dyson, L. E., \& Jones, H. (2017). Mobile learning in higher education in the AsiaPacific region. Singapore: Springer.

Nadkarni, A., \& Hofmann, S. G. (2012). Why do people use Facebook?. Personality and individual differences, 52(3), 243-249. 
Newell, A. (1994). Unified theories of cognition. Harvard University Press.

$\mathrm{Ng}$, M., Chaya, C., \& Hort, J. (2013). The influence of sensory and packaging cues on both liking and emotional, abstract and functional conceptualisations. Food Quality and Preference, 29(2), 146-156.

Ouyang, M., Cai, X., Yin, Y., Zeng, P., Chen, Y., Wang, X., ... \& Wang, P. (2020). Student-student relationship and adolescent problematic smartphone use: The mediating role of materialism and the moderating role of narcissism. Children and Youth Services Review, 104766.

Pontari, B. A., \& Schlenker, B. R. (2000). The influence of cognitive load on self-presentation: Can cognitive busyness help as well as harm social performance?. Journal of personality and social psychology, 78(6), 1092.

Presskorn-Thygesen, T., \& Bjerg, O. (2014). The falling rate of enjoyment: Consumer capitalism and compulsive buying disorder. Ephemera, 14(2), 197.

Raban, D. R., Moldovan, M., \& Jones, Q. (2010, February). An empirical study of critical mass and online community survival. In Proceedings of the 2010 ACM conference on Computer supported cooperative work (pp. 71-80). ACM.

Rizwan, M., Umair, S. M., Bilal, H. M., Akhtar, M., \& Bhatti, M. S. (2014). Determinants of customer intentions for online shopping: A Study from Pakistan. Journal of Sociological Research, 5(1), 248272.

Roberts, J. A., \& Martinez, C. R. (1998). The emerging consumer culture in Mexico: An exploratory investigation of compulsive buying in Mexican young adults. Journal of International Consumer Marketing, 10(1-2), 7-31.

Roy Chaudhuri, H., Mazumdar, S., \& Ghoshal, A. (2011). Conspicuous consumption orientation: Conceptualisation, scale development and validation. Journal of Consumer Behaviour, 10(4), 216-224.

Russell, J. A., \& Mehrabian, A. (1974). Distinguishing anger and anxiety in terms of emotional response factors. Journal of consulting and clinical psychology, 42(1), 79.

Sheikh, J. A., Zafar, B., Pervez, A., \& Bhutta, Z. I. (2016). Smartphone Ergonomics: A Proposal for Older People. In Advances in Ergonomics in Design (pp. 831-841). Springer, Cham.

Söderlund, M. (2002). Customer familiarity and its effects on satisfaction and behavioral intentions. Psychology \& Marketing, 19(10), 861-879.

Sohn, S. H., \& Choi, Y. J. (2014). Phases of shopping addiction evidenced by experiences of compulsive buyers. International Journal of Mental Health and Addiction, 12(3), 243-254.

Soto, C. J., John, O. P., Gosling, S. D., \& Potter, J. (2011). Age differences in personality traits from 10 to 65: Big Five domains and facets in a large cross-sectional sample. Journal of personality and social psychology, 100(2), 330.

Suresh, A. S., \& Biswas, A. (2019). A Study of Factors of Internet Addiction and Its Impact on Online Compulsive Buying Behaviour: Indian Millennial Perspective. Global Business Review, 0972150919857011.

Swann Jr, W. B., Pelham, B. W., \& Krull, D. S. (1989). Agreeable fancy or disagreeable truth? Reconciling self-enhancement and self-verification. Journal of personality and social psychology, 57(5), 782.

Taylor, D. G., \& Strutton, D. (2016). Does Facebook usage lead to conspicuous consumption? The role of envy, narcissism and self-promotion. Journal of Research in Interactive Marketing, 10(3), 231-248.

Taylor, D. G. (2020). Putting the "self" in selfies: how narcissism, envy and self-promotion motivate sharing of travel photos through social media. Journal of Travel \& Tourism Marketing, 37(1), 64-77.

Tiwana, A., \& Bush, A. A. (2005). Continuance in expertise-sharing networks: A social perspective. IEEE Transactions on Engineering Management, 52(1), 85-101.

Turk, D., Janjić, V., Štern, I., Podobnik, M., Lamba, D., Dahl, S. W., ... \& Turk, B. (2001). Structure of human dipeptidyl peptidase I (cathepsin C): exclusion domain added to an endopeptidase framework creates the machine for activation of granular serine proteases. The EMBO journal, 20(23), 6570-6582.

Twenge, J. M., \& Campbell, W. K. (2003). "Isn't it fun to get the respect that we're going to deserve?" Narcissism, social rejection, and aggression. Personality and Social Psychology Bulletin, 29(2), 261272.

Valence, G., d'Astous, A., \& Fortier, L. (1988). Compulsive buying: Concept and measurement. Journal of consumer policy, 11(4), 419-433. 
Veblen, T. (1965). The theory of the leisure class. 1899. AM Kelley, bookseller.

Veblen, T. (2005). Conspicuous consumption (Vol. 38). Penguin UK.

Venkatesh, V. (2000). Determinants of perceived ease of use: Integrating control, intrinsic motivation, and emotion into the technology acceptance model. Information systems research, 11(4), 342-365.

Xu, Y., \& Lee, M. (2020, January). Understanding User Participation and Interaction in Online Shopping Communities from the Social and Relational Perspectives. In Proceedings of the 53rd Hawaii International Conference on System Sciences.

Zhang, K. Z., Xu, H., Zhao, S., \& Yu, Y. (2018). Online reviews and impulse buying behavior: the role of browsing and impulsiveness. Internet Research, 28(3), 522-543.

Zhang, J. H., Bai, Z. Q., Wei, J. X., Yang, M. L., \& Fu, G. F. (2019). The status quo of college students' online shopping addiction and its coping strategies. International Journal of Psychological Studies, 11(2), 88-93.

Zheng, Y., Yang, X., Liu, Q., Chu, X., Huang, Q., \& Zhou, Z. (2020). Perceived stress and online compulsive buying among women: A moderated mediation model. Computers in Human Behavior, 103, 13-20.
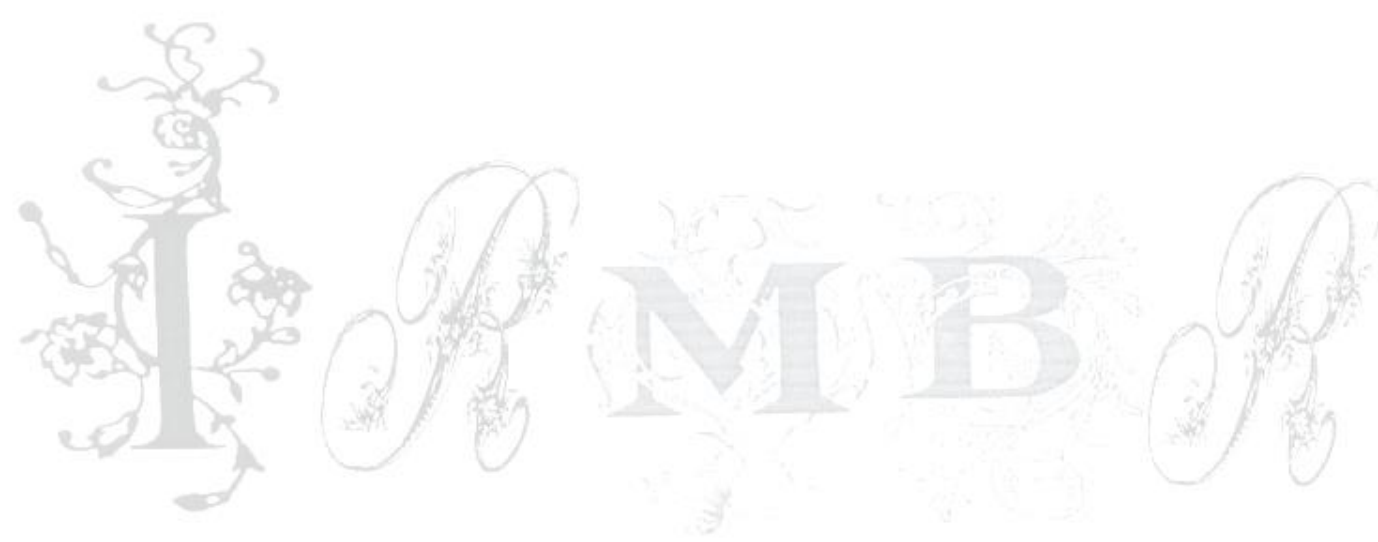